\title{
Cross-categorial modification of properties in Hebrew and English *
}

\author{
Yaron McNabb \\ University of Konstanz
}

\begin{abstract}
Work in the past decade has greatly improved our understanding of the meaning of gradable predicates and degree modification. The discussion of these expressions has charted the way to an examination of additional types of modifiers that do not operate on degrees but rather on context candidates. In this study, I analyze the Hebrew modifier mamaš and its English equivalent really as modifiers of properties of individuals, situations, or propositions. The flexible semantics accounts for these modifiers' wide distribution and types of semantic contribution.
\end{abstract}

Keywords: Modification, Predicates, Adjectives, Epistemic Operators, Negation, Pragmatics

\section{Introduction}

At the centre of the study of gradable predicates is the question of whether these expressions should be analyzed as relations between individuals and degrees or as context-sensitive properties. The debate extends to modifiers of gradable predicates, which can be analyzed as operating on degrees or as operating on worlds and contexts (Klein 1980; Kennedy \& McNally 2005). The Hebrew intensifier mamaš 'really' has a wide syntactic distribution and the ability to modify gradable and non-gradable properties alike. Its distribution suggests that it represents a class of modifiers that do not operate on degrees but rather have a more flexible semantics, in contrast with true degree modifiers like very and slightly.

This paper is structured as follows. In Section 2, I survey the distribution of various types of semantic contribution of mamaš 'really'. In Section 3, I propose that this modifier should be analyzed as a flexible modifier of properties, and present (in Section 3.1) arguments against analyzing it as an epistemic operator. In addition, I show how the various readings resulting from the modifier's interaction with negation are accounted for by the analysis I propose. In Section 4, I discuss an additional

* I would like to thanks Andrea Beltrama, Ryan Bochnak, Camelia Constantinescu, Itamar Francez, Chris Kennedy, Louise McNally, Jason Merchant, Marcin Morzycki, Malte Willer, and audiences at the LSA Annual Meeting in Portland, at which a previous version of this study was presented, and at SALT 22 in Chicago. All remaining errors and inaccuracies are my own.

(C)2012 McNabb 
case, in which mamaš points to a figurative meaning of the expression it modifies, and show that this reading follows from Gricean principles. I conclude in Section 5.

\section{The multiple types of semantic contribution of mamaš 'really'}

\subsection{Mamaš as a degree modifier}

At first blush, the Hebrew modifier mamaš 'really' has the same meaning as me $10 d$ 'very': It boosts the degree of the standard denoted by the gradable predicate it modifies. In both (1a) and (1b), the degree to which the video was cute is said to be notably great.

$$
\begin{aligned}
& \text { a. ze haya sirton mamaš xamud } \\
& \text { this was video.clip really cute } \\
& \text { 'This was a really cute video.' } \\
& \text { b. ze haya sirton me?od xamud } \\
& \text { this was video.clip very cute } \\
& \text { 'This was a really cute video.' }
\end{aligned}
$$

Contrary to first impressions, mamaš does not exhibit the semantic selectional constraints that degree modifiers like very do. But before this contrast is shown, a short discussion of the competing analyses of gradable predicates and degree modification is necessary.

Gradable adjectives are analyzed either as vague predicates or as relations (or measure functions) from degrees to individuals. The vague predicate analysis (Klein 1980) treats gradable adjectives as vague properties, which, like other predicates, denote functions from objects to truth values. The difference between gradable adjectives and non-gradable adjectives is that the domain of gradable adjectives is partially ordered with respect to some property that permits gradation, such as length, weight, or cost. The gradable adjective denotes a function that induces a partitioning on a partially ordered set into objects ordered above and below some point.

The fundamental difference between the vague predicate view and the degree analysis view (e.g. Cresswell 1976; Hellan 1981; Hoeksema 1983; Kennedy 1997), is that unlike the vague predicate approach, which assumes that the domain of a gradable adjective has an inherent ordering, most scalar analyses construct an abstract representation of measurement, a SCALE, and define the interpretation of a gradable adjective in terms of this representation. The scale consists of a set of points or intervals ordered by the relation $\leq$, whereby each point represents a measure or

1 Source: http://www.elsf.net/showthread.php?tt=648631. 
degree of A-ness. Under this analysis, gradable adjectives are relations between an object in a domain and degrees on a scale. In order to determine whether the property denoted by the gradable adjective is true of an individual, it has to be related to a degree on a scale that exceeds a contextually determined standard of comparison. In the vague predicate analysis, the comparison class introduces the set partitioned by the adjective.

When it comes to degree modification, many accounts (e.g. Klein 1980; Kennedy \& McNally 2005) analyze intensifiers like very in a similar way, regardless of how they analyze the modified gradable predicate. The relevant component of these analyses is that, for example, in order for a tree to be very tall, its comparison class must consists of just the trees whose degree of tallness is greater than a contextually-salient standard. Thus, regardless of whether gradable predicates are relations between degrees and individuals, measure functions, or vague properties, in many analyses, the semantics of very is based upon the same contextual parameters (namely, the comparison class) on which the semantics of the gradable predicate it modifies relies, with no direct reference to degrees (even in the degree analysis).

However, unlike me ?od 'very', the intensifier mamaš 'really' can modify nongradable adjectives such as me Porasim 'engaged', as in (2a). The resulting meaning is that the modified predicate is true of the couple under discussion just in case it is true under a strict reading of the predicate, e.g. only after a public engagement ceremony has been conducted in cultures where such a ceremony is necessary.

a. hem mamaš me?orasim

they really engaged.3PL.M

'They are really engaged.'

b. ?? hem me?od me?orasim

they very engaged.3PL.M

'They are really engaged.'

While no work has been done on the prototypical or clear case reading of English really, similar ideas have been discussed in the context of its noun counterpart real (Morzycki 2011; Constantinescu 2011) as well as in accounts of the Washo modifier šemu and the Italian modifier -issimo, which have similar semantic characteristic to really (Bochnak 2011; Beltrama \& Bochnak 2011).

Morzycki argues that real, similarly to true, manipulates scales of prototypicality. For example, "a real idiot is closer to the idiot prototype than a regular idiot" (Morzycki 2011: §4). Hebrew exhibits the parallel between ad-nominal modifiers (e.g. real) and their ad-adjectival counterparts (e.g. really) noted for English. The Hebrew ad-nominal modifier mamaši 'real' patterns like an adjective in that it agrees with the noun it modifies in gender and number (a morphological property degree 
modifiers do not have in Hebrew), as illustrated in (3). In both the attributive and predicative positions, the only available reading in Hebrew is the 'genuine (nonfake)' one and not the degree boosting or prototypical one. Notice that it is the morphology in Hebrew that distinguishes between the prototypical and genuine readings, while it is the attributive/predicative position that does so in English. The ambiguity between genuine distress and a prototypical distress in attributive real is absent in predicative position in English.

a. ha-mexa?a mevatet metsuka mamaši-t the-protest expresses distress.SF real-SF

'The protest expresses real distress.'

b. ha-metsuka še ha-mexa?a mevatet (hi) mamaši-t the-distress.SF that the-protest expresses (is.SF) real-SF

'The distress that the protest expresses is real.'

But while Morzycki's analysis captures well the meaning and semantic selectional restrictions of ad-nomial degree modifiers like real, it does not seem to capture the freer distribution of mamaš and really or the whole array of their semantic contribution. So far, we have seen cases in which mamaš modifies gradable and nongradable adjectives as well as nouns, all of which can be accounted for by Morzycki's analysis. However, such an analysis cannot be extended to cases presented in the following sections, in which mamaš precisifies temporal adverbs and locative expressions as well as modifies events.

\subsection{Mamaš as a precisifier}

Another type of construction in which mamaš 'really' occurs and me Pod 'very' does not is time adverbials. Modification by mamaš 'really' indicates that the time adverbial is used precisely, e.g. Paxšav 'now' refers to the exact time of utterance, as opposed to a longer duration of time preceding and following the time of utterance.
a. ha-ški?a mitraxešet mamaš ?axšav the-sunset happening really now
'The sunset is happening right now.'
b. * ha-ški?a mitraxešet me?od ?axšav the-sunset happening very now
'The sunset is happening right now.'

2 Source: $\mathrm{http}: / /$ twitpic.com/2h7p2k. 
Cross-categorial modification of properties

An additional type of expression in which mamaš acts as a precisifier are locative prepositions, such as be 'in/at'. In (5), mamaš be-merkaz roma indicates that the hotel is right in the centre of Rome. What it means to be in the centre of Rome depends on contextual conditions. For example, in the context of a tourist looking for a hotel, the centre of Rome is the area that includes all of the historical sites; that is, an area that roughly corresponds to the districts (rioni) within the Aurelian Walls. The modifier mamaš picks out this extension and indicates that the hotel is within this area, and perhaps even excludes certain districts whose status as part of the city centre is contested. What is clear is that the hotel is not on the boundary of the city centre or right outside of it.

$$
\begin{aligned}
& \text { ha-malon mamaš be-merkaz roma } \\
& \text { the-hotel really in-center Rome }
\end{aligned}
$$

'The hotel is right in the center of Rome.' ${ }^{3}$

\subsection{Mamaš as an event modifier}

The intensifier mamaš modifies situations as well, like the attacking event denoted by VP in (6). In such cases, the modifier boosts the degree or intensity of the event (e.g. a forceful attack) and in addition indicates that it is a clear case of the situation; that is, the event of attacking satisfies the conditions for a 'real' attack, e.g. a violent, physical attack. $^{4}$

$$
\begin{aligned}
& \text { dani mamaš takaf } \text { Pet moti } \\
& \text { dani really attacked ACC moti }
\end{aligned}
$$

'Danny really attacked Moti.'

Whether mamaš exhibits both types of semantic contribution (intensification and 'clear case') with verbs depends on the type of situation the VP denotes. For example, while a VP with the verb attack denotes a situation that is amenable to a modification of a 'degree' or 'intensity' component (though not by very, to be sure), a verb like cook, as in (7), denotes a situation that is not amenable to intensification. Mamaš bišel 'really cooked' only indicates that the cooking situation was a prototypical one. For example, Danny did not just warm a frozen pizza or a pre-prepared meal, but rather cooked all the dishes from scratch.

3 Source: http://tripintheworld.wikidot.com/forum/t-201814/.

4 Note that what counts as a true case of an attack depends on the context of use. For example, a context of a bar brawl would include a violent physical assault as a true case of an attacking event, whereas a context of an online forum would not. 


$$
\begin{aligned}
& \text { dani mamaš bišel le-moti } \\
& \text { dani really cooked to-moti } \\
& \text { 'Danny really cooked for Moti.' }
\end{aligned}
$$

\subsection{Mamaš as a propositional modifier}

And finally, mamaš cannot occur sentence-initially, either in matrix or embedded sentences, unlike English really, and so clear cases of proposition modification must be sought out elsewhere. In retorts that confirm or deny previous utterances, mamaš occurs before the emphatic ken/lo 'yes/no'. For example, when mamaš scopes over a negated property/proposition, as in (8), it emphasizes its unequivocal, unattenuated denial.

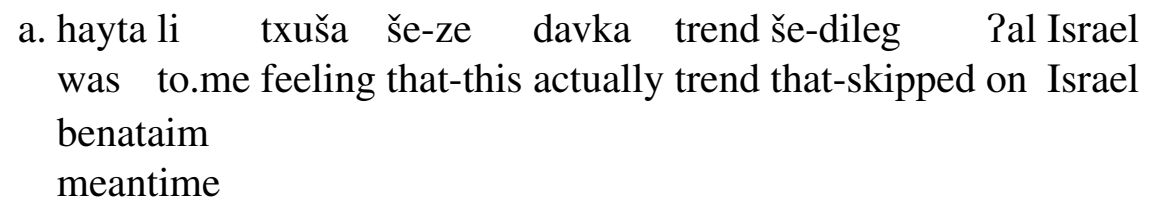

a. hayta li txuša še-ze davka trend še-dileg Pal Israel was to.me feeling that-this actually trend that-skipped on Israel benataim meantime 'I actually had the feeling that this trend skipped Israel for the time being.'

b. mamaš lo dileg really no skipped

'It most certainly didn't (skip Israel)., ${ }^{5}$

Kennedy \& McNally (2005) make similar observations for really. Since distinct degree modifier recursion is not allowed-in contrast with same degree modifier recursion, e.g. very very, quite quite, really really - when co-occuring with other degree modifiers, really can only have the propositional modifier interpretation just in case it is higher in the structure than the other degree modifier(s).

a. * I was very quite surprised.

b. ? I was quite very surprised.

a. * I was quite really surprised.

b. I was really quite surprised.
a. * I was very really surprised.
b. I was really very surprised.
c. I really was very surprised.

5 Source: http://twitter.com/\#!/edvalotan/statuses/32509974504542208. 
Cross-categorial modification of properties

Paradis (2003) likewise notes that where really is projected in the structure affects its interpretation: When it is contained in the structure of the predicate (as in the predicative DegP/AP in 12a or the DP in 12b), it is interpreted as an intensifier; when it occurs higher up in the structure (e.g. when it scopes over the predicative DP in $12 \mathrm{c}$, the VP in $12 \mathrm{~d}$, or the entire TP in 12e), it is interpreted as a propositional modifier.

(12) a. This question is [AP/DegP really surprising $]$.

b. This is [DP a [ really surprising question ] ].

c. This is really [DP a surprising question ].

d. This really [vP is a surprising question ].

e. Really, [TP this is a surprising question ].

Recall that Morzycki analyzes real and similar expressions as ad-nominal degree modifiers that measure the degree of similarity of the property they modify to the prototype of that property. The modifiers mamaš and really, however, do not seem amenable to such an analysis when they are used as propositional modifiers. Unlike real, in a real sportscar, which picks out the most prototypical exemplar of a sportscar, really does not pick out the most prototypical proposition. Rather, the modifier indicates that the speaker is strongly committed to the truth of the proposition.

The challenge here is therefore to construct a uniform semantics that would capture the various types of semantic contribution of mamaš and really. Table 1 summarizes the distribution and semantic contribution of the Hebrew and English expressions. The table shows that the Hebrew and English expressions share all semantic properties except for the inability of English really to combine with PP and time adverbials and therefore to provide the precisifier meaning in those constructions. In the following section, I show that analyzing really and mamaš as modifiers of properties accounts for the distribution and semantic contribution of these expressions.

\section{Crosscategorial modification of properties}

In my analysis of mamaš and really, I draw upon Barker's (2002) analysis of definitely. In order to capture the semantics of modifiers like definitely, Barker contrast them with degree modifiers such as very. Recall that in order to be very tall, one must be sufficiently above a contextually salient standard of tallness. That is, one only needs to look at one context and determine if the individual is very tall given the comparison class in that context. In order to determine whether definitely tall applies to a certain individual, however, it would not suffice to look at one context. 


\begin{tabular}{llll}
\hline Syntactic structure modified & mamaš & really & Semantic contribution \\
\hline AP & $\checkmark$ & $\checkmark$ & Intensifier \\
NP & $\checkmark$ & $*(\mathrm{i})$ & N/A \\
DP & $\checkmark$ & $\checkmark$ & Prototype/Propositional modifier \\
PP/temporal AdvP & $\checkmark$ & $*$ & Precisifier \\
VP & $\checkmark$ & $\checkmark$ & Intensifier/Propositional modifier \\
TP & $\checkmark($ ii) & $\checkmark$ & Propositional modifier
\end{tabular}

Notes: (i) Adjectival real instead; (ii) Must occur after the subject

Table 1 The syntactic distribution and semantic contribution of mamaš and really.

Rather, one would need to look at the individual in the context as a whole (i.e. look at different contexts with different comparison classes) in order to ensure that the relevant property is true of the individual in all context candidates.

These observations are adapted to mamaš (and really), as shown in (13). In prose, mamaš takes a property $P$ that is true of an individual $x$ in context $c$ and returns a property that is true of that individual in all possible contexts just in case there is no other context $c^{\prime}$ in which $P$ is not true of $x$.

(13) The denotation of mamaš, $v .1$ :

Let $C$ be the set of all possible contexts $c$. $\llbracket$ mama $\check{s} \rrbracket=\lambda P \lambda x \lambda c . P(x)$ in $c \in C$ iff $\forall c^{\prime}\left[P(x)\right.$ in $\left.c^{\prime}=1\right]$

The semantics I propose for mamaš 'really' intentionally does not make any reference to degrees or to the type of property that the modifier can combine with, in contrast with Barker's account, which is concerned with the modification of gradable predicates. This is due to the wide distribution of mamaš and its ability to combine with non-gradable properties. The denotation in (13) easily captures the semantic contribution of mamaš when combining with PPs and temporal adverbials. For example, mamaš be-merkaz ha-Pir 'right in the centre of town' is true of an individual if it is in the centre in all context candidates, both strict and non-strict.

Similar accounts have been proposed for expressions with similar properties, such as the intensifier šemu in Washo in (Bochnak 2011) and the suffix -issimo in Italian (Beltrama \& Bochnak 2011). These expressions contrast with mamaš and really in that they are bound morphemes, whereas the Hebrew and English modifiers are free morphemes, a property that enables one to clearly witness the effect of the modifier's position on the available readings (intensifier, precisifier, and propositional modifier). That said, all of these expressions share a reading that many describe as 'epistemic' or 'evidential' (e.g. Paradis 2003; Constantinescu 2011; Beltrama \& 
Bochnak 2011). I will argue next that mamaš and really should not be analyzed as epistemic operators or evidential markers. Rather, it would suffice to analyze them as modifiers of properties (or individuals, situations or propositions), and thus to account for their wide syntactic distribution and flexible semantic contribution, as well as derive the emphatic speaker commitment to the truth of the proposition (i.e. the 'epistemic' reading) as an indirect effect of its non-epistemic semantics.

\subsection{Real(ly) is not an epistemic/evidential modifier}

In this section, I argue against an epistemic analysis of mamaš and very, but before I do so (in Section 3.1.2), I briefly summarize the epistemic analysis of real(ly) (in Section 3.1.1).

\subsubsection{The semantics of an epistemic modifier}

As mentioned in the previous section, Paradis (2003) discusses the effect of the sentential position of really on the availability of the degree ('scalar') and the epistemic readings. She argues that in fact all of these cases are "expressive of epistemic commitment", but in the cases of degree modification, the epistemic commitment is a result of the degree modification. While it is clear that asserting that an individual is really $P$ entails that the property $P$ is true of that individual, the idea that the epistemic commitment is a consequence of degree modification requires that there be separate mechanisms to derive the epistemic readings in cases with and without degree modification involving really. The unified semantics I propose here, in which really indicates that a property holds of an individual in all possible context candidates, derives all the attested readings without requiring that they be derived from each other or that one type of modification (e.g. degree modification) may always lead to epistemic commitment.

Constantinescu (2011), who focusses on the adnominal modifier real, argues for a uniform analysis that does not involve degree modification. She argues instead that the apparent degree reading is derived from the basic epistemic meaning of real. Under her analysis, $x$ is a real $P$ just in case the property $P$ holds in all of the speaker's doxastic alternatives; that is, $x$ is in the positive extension of $P$ in the speaker's belief world. And thus, when using real, the speaker emphasizes that she has good reasons to describe $x$ as $P$ because $x$ clearly displays the characteristics that typically define $P$ in her opinion (Constantinescu 2011: 201-207). ${ }^{6}$

6 Both Paradis and Constantinescu label the expressions under discussion as 'evidental'. I sidestep the question of whether this type of expression should receive the 'evidential' label, as I believe this should be included in a discussion that details the properties of evidential markers. Most studies on evidential markers discuss expressions that in fact encode the source of information, a property that 
In what follows, I show that really does not possess properties that run-of-themill epistemic modals do, namely the unembeddability of epistemic modals and their restricted distribution. These facts lend support to the semantics I propose here for mamaš and really (with certain caveats in order to account for the few differences between the modifiers).

\subsubsection{Epistemic modals cannot be embedded; really can}

Subjective epistemic modals - as well as some non-modal epistemic adverbs, such as possibly (Lyons 1977) — cannot be embedded in the complement of factive verbs (14a), verbs of telling (14b) and in antecedents of conditionals (14c) (Papafragou 2006; Portner 2009). Embedding the modal must in the sentences in (14) results in odd or hard-to-interpret propositions.

(14) a. ? It is surprising that Superman must be jealous of Lois.

b. ? Spiderman told me that Superman must be jealous of Lois.

c. ? If Max must/may be lonely, his wife will be worried.

The intensifiers mamaš and really, on the other hand, are felicitous in these constructions. For example, when a property of individuals such as is tall is modified by mamaš 'really', as in (15a), the most accessible reading is the degree-boosting one. When the modified adjective is embedded under a factive predicate such as maftia 'surprising' (15b) or in the antecedent of a conditional (15c), the sentence is felicitous. This is in contrast with a sentence containing the epistemic adverb betax 'surely' (16a), whose embedding under a factive predicate, as in (16b), or in the antecedent of a conditional, as in (16c), is infelicitous.

a. na?ama mamaš gvoha

Naama really tall.FS

'Naama is really tall.'

b. Context: all of Naama's family members are short.

ze maftia še na?ama mamaš gvoha

this surprising that Naama really tall.FS

'It's surprising that Naama is really tall.'

c. Pim na?ama mamaš gvoha, hi yexola le-hitstaref le-kvutsat

if Naama really tall.FS, she can.FS to-join to-team

ha-kadursal

the-basketball

mamaš, really, etc., which only indicate the commitment the speaker has toward a property, do not possess. Contrast He really is a good singer with I heard from Juliana that he is a really good singer. 
Cross-categorial modification of properties

'If Naama is really tall, then she can join the basketball team.'

a. na?ama betax gvoha

Naama surely tall.FS

'Naama is surely tall'; 'I bet Naama is tall.'

b. ? ze maftia še na?ama betax gvoha

this surprising that Naama surely tall.FS

'? It's surprising that Naama is surely tall.'

c. ? Pim na?ama betax gvoha, hi yexola le-hitstaref le-kvutsat

if Naama surely tall.FS, she can.FS to-join to-team

ha-kadursal

the-basketball

'? If Naama is surely tall, then she can join the basketball team.'

If embedding modified adjectives highlights the intensifying meaning, embedding a modified verb highlights the intensified or prototypical readings, as shown in (17). In (17a), for example, the speaker is surprised at the fact that the attacking event was intense (the degree-boosting meaning) or violent (the prototypical meaning). (Note that both readings may overlap: cases of intense attacks share many properties with cases of prototypical, perhaps violent, attacks, e.g. a physical assault performed by the agent, aggression exhibited by the agent, and injury to the patient as a result.) In (17b-c) likewise the event warrants a report to the police or their involvement in the case either if it qualifies as an attacking event (prototypical reading) or if it was violent or extreme enough (degree-boosting reading).

a. dani mamaš takaf ?et moti dani really attacked ACC moti

'Danny really attacked Moti.'

b. Context: Danny is always even-tempered and restrained.

ze maftia še dani mamaš takaf ?et moti

this surprising that dani really attacked ACC moti

'It's surprising the Danny really attacked Moti.'

c. Pim dani mamaš takaf Pet moti Paz yeš le-moti siba tova if dani really attacked ACC moti then there.is to-moti reason good le-daveax al ze la-mištara to-report on this to.the-police

'If Danny really attacked Moti then Moti has a good reason to report the case to the police.' 
d. ha-mištara hayta be-safek še-dani mamaš takaf Pet moti the-police.FS was.FS in-doubt that-dani really attacked ACC moti 'The police doubted that Danny really attacked Moti.'

As mentioned already in Section 2.3, whether an activity receives the intensified meaning or not depends on the denotation of the verb. This means that in cases in which a verb that does not denote a scalar property, e.g. buy, the only available reading will be a prototypical one, as illustrated in (18), where the speaker explicitly describes what a real case of buying would be. (And an intense situation of buying is not a possible situation.)

[...] laxen kaniti - mamaš kaniti be-kesef tov ve-male, 60

[...] therefore bought.1s - really bought.1s in-money good and-full, 60

šekel be-muzika neto — ?et ha-xadaš šel REM

shekel in-Music Neto - ACC the-new POSS REM

'[... T]hat's why I bought — really bought, in full price, 60 NIS at Muzika Neto [a Music Store] — the new one by REM.' 7

In conclusion, mamaš 'really' is a modifier of properties of individuals, eventualities, or propositions, such that mamaš $P$ is true of an individual if $P$ is true of that individual in all contexts candidates. The same denotation can be applied to English really with the exception of time and locative adverbials, in which right is felicitous (e.g. right now, right in the middle). I leave the reasons for the inability of really to modify time and locative adverbials to future research, though note that a lexical application of the Elsewhere Condition (Kiparsky 1973) accounts for the distribution: Right can only modify time and locative adverbials, whereas really applies elsewhere. However, future investigation may show that the semantic properties of these expressions that are in competition here account for their complementary distribution.

(19) The denotation of mamaš, final version:

Let $C$ be the set of all relevant possible contexts $c$.

Let $P$ be a property of $\sigma, \sigma$ is an individual, an event(uality), or a proposition. $\llbracket$ mama ̌ $\rrbracket=\lambda P \lambda \sigma \lambda c . P(\sigma)$ in $c \in C$ iff $\forall c^{\prime}\left[P(\sigma)\right.$ in $\left.c^{\prime}=1\right]$

\subsection{Domain widening and mamaš}

As mentioned above, mamaš and really pick out a property in a certain context and return a property that is true of an individual, situation or proposition in a larger

7 Source: http://www.nrg.co.il/online/47/ART2/222/706.html. 
set of context candidates. This is akin to domain widening in the spirit of Kadmon \& Landman (1993), whereby a domain widener removes contextual restrictions on a quantified expression. ${ }^{8}$ Anderssen (2006) draws a parallel between domain widening in quantifiers and domain widening of comparison classes, which provide the contextual argument in gradable adjectives. In his analysis of the German adverb überhaupt as a domain widener, Anderssen notes that this adverb can combine with predicate adjectives, such as gro $\beta$ 'tall' in (20). Anderssen argues that überhaupt quantifies over the variable over comparison classes and widens the domain to include additional comparison classes.

(20) a. Richard ist ganz schön groß für einen noch nicht Ausgewachsenen.

Richard is quite tall for a yet not grown-up

'Richard is quite tall for somebody who is still growing up.' $\quad(=18 \mathrm{a})$

b. Richard ist überhaupt ganz schön groß.

Richard is überhaupt quite tall

'Richard is quite tall in general.' $\quad(=18 \mathrm{~b})$

For example, in (20a), Richard is quite tall for a comparison class that includes only individuals that have not yet completed their growth, thereby setting a low standard of comparison for height. In contrast, the comparison class in (20b) includes additional classes, such as fully developed individuals, raising the standard of comparison for height. Anderssen does not include examples without the degree modifier ganz schön 'quite' and without überhaupt, but the domain widening effect occurs also in such cases: The gradable predicate gro $\beta$ 'tall' would be evaluated against a contextually determined (and constrained) comparison class; überhaupt gro $\beta$, on the other hand, would be evaluated against a wider comparison class that includes individuals that would have otherwise be excluded by the context.

Just like the inclusion of additional comparison classes could raise the standard of comparison for a gradable predicate, it could also lead to its lowering, if the comparison classes include individuals with an aggregate lower standard of comparison. In order to prevent this unfortunate consequence, Anderssen states that threshold values corresponding to different comparison classes are ordered, and that this ordering translates into an ordering by semantic strength. And so, the standard of comparison resulting from domain widening will always be the highest one.

Morzycki (To appear) analyzes adverbs like remarkably as domain wideners as well, but in his account, these adverbs operate on degrees. More specifically, the degrees included in the unwidened domain are excluded when an adverb like remarkably modifies a gradable predicate. For example Clyde is remarkably tall is

8 I owe this idea about the parallel between modifiers like mamaš and domain widening to Andrea Beltrama. 
true just in case the degree to which Clyde is tall is greater than the standard and is in the portion of the widened domain that excludes the original domain.

While I agree that Morzycki's explicit formalization of the exclusion of contexts in the unwidened domain for the semantics of adverbs like remarkably has the welcome consequence of preventing the generation of a lower standard of comparison for the modified gradable predicate, I do not believe this careful definitional addition is necessary for expressions like really. Really $P$ requires that $P$ be true in all context candidates, and so it does not highlight a difference between the unwidened domain that $P$ applies in and the widened domain that really $P$ applies in. In contrast, remarkably $P$ adds additional information about $P$ (that the degree of $P$ is remarkable) and unbelievably $P$ points to the unbelievability of the degree of $P$; that is, the exclusion of cases in which $P$ holds of $x$ but the degree of $P$ is not remarkable or unbelievable.

In addition, mamaš and really combine with a much larger set of expressions than adverbs like remarkably do, most importantly non-gradable predicates. If a semantics of domain widening is developed for expressions like mamaš and really, it must encode the compatibility of these modifiers with various predicates, as in the analysis argued for in this paper. I leave it to future research to adjudicate between the domain widening analysis and the quantification over context candidates analysis (the one argued for here), but as it stands, they do seem to share many properties.

\subsection{Modifying properties over and under negation}

When mamaš 'really' and the property it modifies are embedded under negation, the resulting meaning is attenuated. The sentence in (21) leads to the following reading and inference: that the speaker does not count the emotional effect she experienced as a real case of excitement. The additional inference is that the speaker did not get excited at all, but she is reluctant to say so explicitly, possibly out of politeness or because she does not want to commit to the proposition (Bolinger 1972; Ducrot 1973; Horn 2001).

$$
\begin{aligned}
& \text { lo mamaš hitragašti } \\
& \text { no really excited.1s } \\
& \text { 'I didn't really get excited.' }
\end{aligned}
$$

The analysis of mamaš 'really' predicts the two readings. The modified property really get excited is true of an individual just in case get excited is true in all possible, relevant context candidates. The negation of the modified property indicates that the event of the speaker's getting excited is not a real case of said property (i.e. it

9 Source: http://cafe.themarker.com/post/1996926/. 
would not qualify as such in all possible context candidates). The resulting meaning leads to two readings. Under the first reading, the speaker got excited (only) in some $c \mathrm{~s}$; that is, it is in the positive extension of getting excited, but it does not qualify as a clear or extreme case of getting excited. Under the second reading, the speaker did not get excited or the event is in the extension gap of getting excited (i.e. the speaker 'sort of' got excited). And indeed these are the two readings available for the sentence in (21).

When mamaš and really scope over the negated property/proposition, we get their unequivocal, unattenuated denial, as illustrated by B's utterance, given here again (see 8 for the complete exchange). The resulting meaning is due to the modification of the entire, negated proposition, as sketched in (22b). B says that the trend did not skip Israel in all possible context candidates. In addition to the unequivocal denial of the proposition The trend skipped Israel, the speaker asserts that she has every reason to believe that the negated proposition is true. That is, the epistemic force is a side-effect of the negation of a modified proposition with no need for additional semantic machinery.

\section{a. B: mamaš lo dileg} really no skipped

'It most certainly didn't $\langle$ skip Israel $\rangle$.'

b. «It mamaš didn't skip Israel $\rrbracket=1$ iff

The trend didn't skip Israel in any $c \in C$.

And since mamaš 'really' is not an epistemic operator, it can be embedded in the antecedent of a conditional, as illustrated in (23).

im ha-trend mamaš lo dileg, az ex at masbira ?et ze if the-trend really no skipped, then how you.3FS explain.FS ACC this še af-exad lo yode?a al ze?

that n-one no know.SM on this?

'If the trend absolutely didn't skip Israel, then how do you explain the fact that no knows about it?'

\section{Literal meaning, metaphors, and the semantics-pragmatics interface}

An additional set of expressions mamaš 'really' modifies are expressions that are ambiguous between a literal and a metaphorical meaning, like the NP mixre zahav 'gold mine' in (24), which may be used to refer to a place where gold is mined or to a (tangible or abstract) source of wealth and resources. In the example below, it is the metaphorical sense that is used, and mamaš modifies that sense only: Eyn 
Zahav Park (literally, 'the Golden Spring') is truly a place of rich of resources, e.g. activities for children, great vista points, various trails, etc.

eyn zahav hu mamaš mixre zahav

spring gold is really mine gold

'The Golden Spring (= Eyn Zahav Park) is a real gold mine.' 10

The Hebrew modifier, then, targets a certain sense (namely, the metaphorical sense) and expresses the speaker's commitment to that sense. Under this reading, mamaš has a similar meaning to English literally, as shown in (25).

"If we do not act now, homosexuals will own America! If you and I do not speak up now, this homosexual steamroller will literally crush all decent men, women and children who get in its way..."

Rev. Jerry Falwell, People for the American Way, "Hostile Climate," 1997, p. 15

Similarly to mamaš in (24), literally in (25) indicates that the speaker is only committed to the metaphorical meaning of crush, not the deforming and compressing that an actual steamroller would do.

Israel (2002) argues that literally points to the speaker's commitment to the use of expressions rather than its literal content. When there is no metaphorical sense available, literally adds a verum or speaker commitment meaning to the proposition (26), and when the modified expression is used in its metaphorical sense, the speaker is commited to the figurative meaning of the modified expression (27).

(26) [Trump] felt that baldness is a sign of weakness and I think he felt literally that he could control it. (Israel 2002: example 9a, PC)

(27) The students were literally riveted to their chairs.

Capturing the meaning of mamaš when it modifies figurative language may be possible under the current semantics by restricting the contexts to those in which the modified expression denotes only the metaphorical (and not the literal) meaning. This is similar to how mamaš picks out only the senses of, e.g., attack that are relevant to the situational and conversational context. More specifically, mamaš is inferred as picking out the figurative meaning, when available, as a result of the speaker's violation of the Maxim of Quality (Grice 1975). Since in a usual (and desirable) situation, students are not fastened to their chairs with rivets, the speaker, uttering (27), flouts the Maxim of Quality by being literally false, and so the listener is being led to infer that the speaker uses figurative language to mean that the students are engrossed and fascinated (Grice 1989: 34).

10 Source: http://www.teva.org.il. 
Cross-categorial modification of properties

\section{Conclusion}

The Hebrew modifier mamaš and its approximate English counterpart really were shown to be modifiers of properties of individuals, situations, and propositions. Their semantic contribution is to indicate that the property they modify holds in all possible contexts, thereby indirectly giving rise to the observed readings of intensification (or degree boosting), precisification, prototypicality, and epistemic force. The flexible semantics argued for here accounts for the variety of expressions these modifiers can combine with as well as the various types of semantic contribution.

Mamaš and really thus represent a type of modification that involves quantification over context candidates, and which joins a family of expressions that includes other types of modification, such as quantification over individuals, degrees, or situations. In addition, mamaš and really are representatives of a class of vague modifiers (like perfectly and sort of) that are used to manage vagueness and precision by manipulating the context and that exist side by side with true degree modifiers, such as completely and half, as part of a typology of predicate modification.

\section{References}

Anderssen, Jan. 2006. Generalized domain widening überhaupt. In Donald Baumer, David Montero \& Michael Scanlon (eds.), Proceedings of the 25th West Coast Conference on Formal Linguistics, Somerville, MA: Cascadilla Proceedings Project.

Barker, Chris. 2002. The dynamics of vagueness. Linguistics and Philosophy 25(1). $1-36$.

Beltrama, Andrea \& M. Ryan Bochnak. 2011. Intensification without degrees cross-linguistically. In Workshop on Modification (With \& Without Modifiers), Madrid.

Bochnak, M. Ryan. 2011. Managing vagueness, imprecision and loose talk in Washo: the case of šemu. In Semantics of Underrepresented Languages of the Americas 6, Manchester, UK.

Bolinger, Dwight Le Merton. 1972. Degree Words. The Hague: Mouton.

Constantinescu, Camelia. 2011. Gradability in the Nominal Domain: Universiteit Leiden dissertation.

Cresswell, Maxwell John. 1976. The semantics of degree. In Barbara Partee (ed.), Montague Grammar, 261-292. New York: Academic Press.

Ducrot, Oswald. 1973. La Preuve et le Dire: Langage et Logique. Paris: Maison Mame.

Grice, H. Paul. 1975. Logic and conversation. In D. Davidson \& G. Harman (eds.), The Logic of Grammar, 64-75. Encino, CA. 
Grice, H. Paul. 1989. Studies in the Way of Words. Cambridge, Mass: Harvard University Press.

Hellan, Lars. 1981. Towards an Integrated Analysis of Comparatives. Tübingen: Narr.

Hoeksema, Jack. 1983. Negative polarity and the comparative. Natural Language \& Linguistic Theory 1(3). 403-434.

Horn, Laurence R. 2001. A Natural History of Negation. Stanford, CA: CSLI.

Israel, Michael. 2002. Literally speaking. Journal of Pragmatics 34(4). 423-432.

Kadmon, Nirit \& Fred Landman. 1993. 'Any'. Linguistics and Philosophy 16(4). 353-422.

Kennedy, Christopher. 1997. Projecting the Adjective: The Syntax and Semantics of Gradability and Comparison. Published in 1999 by Garland, New York.: University of California at Santa Cruz dissertation.

Kennedy, Christopher \& Louise McNally. 2005. Scale structure, degree modification, and the semantics of gradable predicates. Language 81(2). 345-381.

Kiparsky, Paul. 1973. "Elsewhere" in Phonology. In S. Anderson \& P. Kiparsky (eds.), A Festschrift for Morris Halle, 93-106. Holt, Rinehart \& Winston.

Klein, Ewan. 1980. A semantics for positive and comparative adjectives. Linguistics and Philosophy 4(1). 1-45.

Lyons, John. 1977. Semantics. Cambridge University Press.

Morzycki, Marcin. 2011. The several faces of adnominal degree modification. In Jaehoon Choi, E. Alan Hogue, Jeffrey Punske, Deniz Tat, Jessamyn Schertz, \& Alex Trueman (eds.), Proceedings of the 29th West Coast Conference on Formal Linguistics, Somerville, MA: Cascadilla Proceedings Project.

Morzycki, Marcin. To appear. Adverbial modification of adjectives: Evaluatives and a little beyond. In Johannes Dölling \& Tatjana Heyde-Zybatow (eds.), Event Structures in Linguistic Form and Interpretation, Mouton de Gruyter.

Papafragou, Anna. 2006. Epistemic modality and truth conditions. Lingua 116. $1688-1702$.

Paradis, Carita. 2003. Between epistemic modality and degree: The case of really. Topics in English Linguistics 44. 191-222.

Portner, Paul. 2009. Modality. Oxford, UK: Oxford University Press.

Yaron McNabb

University of Konstanz

Department of Linguistics

P.O. Box 216

78457 Konstanz, Germany 